\title{
The evolution of a 'one-stop' outpatient manual vacuum aspiration service for termination of pregnancy
}

\author{
Joanna Speedie, ${ }^{1}$ Stephen Robson ${ }^{2}$
}

\begin{abstract}
${ }^{1}$ Sexual Health Services, New Croft Centre, Newcastle upon Tyne, UK

${ }^{2}$ Institute of Cellular Medicine, Uterine Cell Signalling Group, The Medical School, Newcastle University, Newcastle upon Tyne, UK
\end{abstract}

\section{Correspondence to}

Dr Joanna Speedie, Sexual Health Services, New Croft Centre, Newcastle upon Tyne NE1 6ND, UK; joannaspeedie@googlemail. com

Received 23 April 2017 Revised 17 October 2017 Accepted 21 October 2017 Published Online First 16 November 2017
CrossMark

To cite: Speedie J, Robson S. BMJ Sex Reprod Health 2018;44:58-60.

\section{WHY WAS CHANGE NEEDED?}

In 2015 over 185000 women in England and Wales underwent a termination of pregnancy (TOP) $)^{1}$ and $80 \%$ of these were performed at 3-9 weeks of pregnancy. ${ }^{1}$ The majority of early procedures (63\%) were performed using medical methods. ${ }^{1}$ Manual vacuum aspiration (MVA) under local anaesthetic was initially designed to be used in resource-poor settings for uterine evacuation following incomplete miscarriage. ${ }^{2}$ Use of the procedure was then broadened to include TOP. A systematic review comparing MVA with electric vacuum aspiration (EVA) found that MVA was associated with comparable rates of complete uterine evacuation, but less pain and blood loss. ${ }^{3}$ Women found the two procedures equally acceptable. ${ }^{3}$ As a result, MVA is now routinely used in many developed countries for the management of both miscarriage and TOP. More recent UK data has highlighted the cost effectiveness and acceptability of MVA using local anaesthetic. ${ }^{4}$ However, despite the evidence regarding the effectiveness and acceptability of MVA, the procedure has not been widely adopted in the UK. As a result of this evidence we decided to introduce a MVA service to increase women's choice when accessing an abortion.

\section{HOW DID WE GO ABOUT} IMPLEMENTING CHANGE?

The MVA TOP service at Newcastle upon Tyne NHS Foundation Trust was set up by SR who had extensive experience of performing EVA under general anaesthesia up to 15 weeks' gestation. A business case for the service was approved by the Trust. Patient information about MVA was developed and added to the Trust's TOP web page. ${ }^{5}$ Nurse practitioners, who conduct all TOP assessment clinics, were educated about the procedure and which patient groups would be appropriate.

\section{Phase I}

The service was introduced in the Women's Health Unit in 2009 with a maximum of two procedures per week. The Unit offers outpatient clinics and procedures (eg, hysteroscopy) and has dedicated access to ultrasound scanning. Nurse practitioners could directly book healthy women up to $10^{+0}$ weeks' gestation, confirmed by ultrasound, for MVA. In general, women were able to access MVA within 1-2 weeks following the initial outpatient assessment.

Women self-administered $400 \mu \mathrm{g}$ misoprostol vaginally approximately 2 hours pre-procedure. They were simultaneously given azithromycin $1 \mathrm{~g}$ and codeine phosphate $30 \mathrm{mg}$ orally. MVA was performed in the lithotomy position. Following a bimanual vaginal examination, a Cusco speculum was inserted and the cervix visualised. Lidocaine hydrochloride $2 \%$ (4-5 mL) with epinephrine 1:80000 were injected intracervically at 12, 3, 6 and 9 o'clock using a dental syringe with a $35 \mathrm{~mm} \times 0.4 \mathrm{~mm}$ Solo Supra needle. Cervical dilation was subsequently performed (if needed) using graded Hegar dilators. A flexible cannula (Woman Care Global) was then attached to a $60 \mathrm{~mL}$ double-valve aspirator (Woman Care Global) with a self-locking mechanism. The cannula size in millimetres selected was generally equivalent to the number of weeks of gestation. Uterine aspiration was then performed and repeated until no new products of conception (POC) were obtained and the uterus felt empty. An abdominal ultrasound scan was then performed to check that the uterine cavity 
was empty. Rarely, where it was not possible to visualise the uterus clearly transabdominally, a transvaginal scan was performed. Metronidazole $1 \mathrm{~g}$ was administered rectally. If the woman had opted for a contraceptive implant or an intrauterine contraceptive device this was then inserted. POC were examined to confirm the presence of chorionic villi. Throughout the procedure women had the option of using Entonox for pain relief if necessary.

A review of the service in 2014 showed that few women were choosing MVA. A service evaluation which included a patient satisfaction survey was therefore performed. Results revealed a clear preference for quick access to TOP, with half the women stating that they would have wished to have the procedure on the same day as their initial consultation.

\section{Phase II}

A pilot study was performed over a 6-month period to assess the acceptability of a 'one-stop' MVA service for women up to $9^{+0}$ weeks' gestation. The clinic and same-day MVA service were provided by JS who had been trained in MVA by both SR and the British Pregnancy Advisory Service. A revised limit of $9^{+0}$ weeks was chosen to reflect JS's experience.

Women contacting or referred to the TOP service who were less than $9^{+0}$ weeks' gestation according to their last menstrual period were offered assessment at the one-stop clinic. Women interested in attending that clinic were e-mailed information regarding management options including MVA, surgical TOP and medical TOP. The information clearly stated that MVA would only be possible if the patient was at no more than $9^{+0}$ weeks' gestation and sure of her decision. Four clinic assessment slots were available between 09:00 and 11:00 and MVAs were performed once the clinic had finished. Access to MVA was also available via other TOP clinics run by nurse practitioners. A maximum of six MVA slots were available each week.

\section{HOW WAS CHANGE EVALUATED?}

The following outcomes were routinely collected onto a bespoke Microsoft Excel database:

- Patient demographics

- Blood loss (overall volume of aspirated blood and POC in the syringe)

- Number of aspirations required to complete uterine evacuation as confirmed by ultrasound

- Pain score - post-procedure women were asked to record the maximum pain experienced during the procedure using a $10 \mathrm{~cm}$ visual analogue scale (VAS) ${ }^{6}$

- Acceptability of MVA as assessed by asking the woman if she would choose the same procedure again if she needed to have another TOP

- Side effects (eg, vomiting, diarrhoea)

- Complications.
WAS THE CHANGE BENEFICIAL?

\section{Phase I}

Between 2009 and 2014, 72 MVAs were performed (table 1).

One woman had a complicated procedure; cervical dilatation was difficult and complete uterine evacuation was not achieved, requiring evacuation of retained POC under general anaesthetic. Fifty-eight (80.6\%) women stated that they would have MVA again.

\section{Phase II}

Ninety-three women were seen at the one-stop clinic. Seventy-five had a viable pregnancy of $\leq 9^{+0}$ weeks' gestation on ultrasound scan, of whom 70 decided to undergo TOP; 52 opted for MVA and 51 had the procedure on the same day. One woman returned for MVA the following week at her request. Twenty women who attended other TOP clinics opted for MVA. Thus 72 MVAs were performed during the 6-month pilot (table 1), of which $71 \%$ were same-day MVAs. By chance the number of women in Phases I and II was identical.

Three women experienced complications. Two procedures were abandoned as cervical dilatation was difficult and one patient returned with vaginal bleeding at 1 week; an ultrasound scan was reported as showing retained POC and surgical evacuation was performed. Sixty-three (88\%) women stated that they would have MVA again, six (8\%) stated that they would not, and no data were recorded for three (4\%) women. All women who had a same-day MVA stated that they thought this clinic was a good idea and that they would recommend it to a friend.

To our knowledge this is the first report of a one-stop service for MVA that was specifically established as a one-stop service with a consistent care pathway in place. We found that offering women the

\begin{tabular}{|c|c|c|}
\hline Characteristic & $\begin{array}{l}\text { Phase I } \\
(n=72)\end{array}$ & $\begin{array}{l}\text { Phase II } \\
(n=72)\end{array}$ \\
\hline Age in years (median) & $17-40(27)$ & $16-44(29)$ \\
\hline Parity (median) & $0-7(1)$ & $0-5(1)$ \\
\hline Gestational age in weeks (median) & $6^{+2}-10^{+2}(8)$ & $6^{+0}-9^{+0}(7)$ \\
\hline Estimated blood loss in mL (median) & $15-125(55)$ & $5-100(20)$ \\
\hline Cannula size used (median) & $5-9(7)$ & $5-9(6)$ \\
\hline $\begin{array}{l}\text { Number of aspirations needed } \\
\text { (median) }\end{array}$ & $2-6(2)$ & $1-6(2)$ \\
\hline Entonox use (\%) & 16.6 & 36.0 \\
\hline Vomiting (\%) & 2.8 & 6.0 \\
\hline $\begin{array}{l}\text { Pain visual analogue score (VAS) } \\
\text { (median) }\end{array}$ & $0-9.3(3.5)$ & $0-9.6(3.5)$ \\
\hline Complications (\%) & 1.4 & 4.0 \\
\hline $\begin{array}{l}\text { Long-acting reversible contraception } \\
\text { (LARC) uptake (\%) }\end{array}$ & 51.4 & 68.0 \\
\hline
\end{tabular}


opportunity to have a procedure on the same day strongly influenced their choice; the much higher take up of MVA in Phase II strongly suggests that having timely access to TOP is more important to women than the choice of procedure. Many women work full time or have children and may struggle to attend multiple hospital appointments at short notice. As MVA avoids a general anaesthetic or sedation women can come to the appointment by themselves and are usually able to leave soon afterwards and drive home. This supports women's right to confidentiality.

\section{WHAT CHALLENGES WERE THERE?}

Prior to 2009 there were no training courses available for MVA within the UK, therefore SR had to teach himself the technique by reading relevant literature and performing the technique in consented women under general anaesthesia. The Royal College of Obstetricians and Gynaecologists now runs an approved MVA training course annually. Initially nursing staff attitudes to MVA were somewhat negative, and this may have influenced the take up of MVA in Phase I. Prior to the establishment of the one-stop MVA service much work was done to educate staff members that the procedure was effective and acceptable.

\section{WHAT ADVICE WOULD YOU GIVE TO OTHERS?}

Hospital procedures for approving new procedures vary but such approval is a necessary prerequisite to establishing a service. Physicians performing MVA must be appropriately trained. The clinical environment is important to the success of a service. A one-stop clinic should be located in a well-equipped and staffed environment where consultations and procedures can both be performed.

Contributors SR and JS set up the service together. JS carried out the patient questionnaire. JS wrote the paper with the assistance of SR.

Competing interests None declared.

Provenance and peer review Not commissioned; externally peer reviewed.

(C) Article author(s) (or their employer(s) unless otherwise stated in the text of the article) 2018. All rights reserved. No commercial use is permitted unless otherwise expressly granted.

\section{REFERENCES}

1 Department of Health. Abortion statistics England and Wales 2015, 2016. https://www.gov.uk/government/uploads/system/ uploads/attachment_data/file/570040/Updated_Abortion_ Statistics_2015.pdf (accessed 11 Jan 2017).

2 Magotti RF, Munjinja PG, Lema RS, et al. Cost-effectiveness of managing abortions: manual vacuum aspiration (MVA) compared to evacuation by curettage in Tanzania. East Afr Med J 1995;72:248-51.

3 Wen J, Cai QY, Deng F, et al. Manual versus electric vacuum aspiration for first-trimester abortion: a systematic review. BJOG 2008;115:5-13.

4 Pillai M, Welsh V, Sedgeman K, et al. Introduction of a manual vacuum aspiration service: a model of service within a NHS Sexual Health Service. J Fam Plann Reprod Health Care $2015 ; 41: 27-32$.

5 Newcastle upon Tyne hospitals NHS Foundation Trust. Termination of pregnancy. http://www.newcastle-hospitals.org. uk/services/gynaecology_services_termination-of-pregnancy.aspx (accessed 18 Jan 2017).

6 Bijur PE, Silver W, Gallagher EJ. Reliability of the visual analog scale for measurement of acute pain. Acad Emerg Med 2001;8:1153-7.

\section{Readers' contributions invited on 'Better Way of Working'}

The journal publishes occasional 'Better Way of Working' articles, the purpose of which is to disseminate service delivery suggestions likely to be of interest and relevance to the journal's readership. Readers are invited to submit suggestions based on their own personal experience for consideration by the Editor-in-Chief. Contributions normally should not exceed 1200 words and should be written in a standardised format responding to the following four questions (or similar): Why was change needed? How did you go about implementing change? What advice would you give to others who might be considering a similar course of action? How did you show that the change had occurred? All contributions should be submitted via the journal's online submission system at http://mc.manuscriptcentral.com/bmjsrh. 